\title{
ACUMULAÇÃO PRIMITIVA, CAPITAL FICTÍCIO E ACUMULAÇÃO POR ESPOLIAÇÃO: INTRODUÇÃO A UMA LEITURA GEOGRÁFICA DA ECONOMIA CAPITALISTA CONTEMPORÂNEA
}

Primitive accumulation, Fictitious Capital and Accumulation by dispossession: introduction to a geographical reading of the contemporary capitalist economy

José Arnaldo dos Santos Ribeiro Júnior Mestrando em Geografia Humana FFLCH/USP aj_ramone@hotmail.com

Artigo recebido em 24/03/2013 e aceito para publicação em 10/12/2013

DOI: $10.12957 /$ tamoios.2014.5354

Resumo

Abstract
Este trabalho busca introduzir uma leitura geográfica da economia política contemporânea enfatizando a relação entre a acumulação primitiva, capital fictício e acumulação por espoliação. Primeiro retorna-se ao conceito marxiano de acumulação primitiva. Em seguida, baseando-se em F. Chesnais, estabelece-se a relação da acumulação primitiva com o capital fictício. Por fim, pontua-se a dialética entre os dois fenômenos e o conceito de acumulação por espoliação de D. Harvey

Palavras-chave: Acumulação primitiva. Capital Fictício. Acumulação por espoliação. Economia Política.

This paper seeks to introduce a geographical reading of contemporary political economy emphasizing the relationship between primitive accumulation, the fictitious capital and accumulation by dispossession. First returns to the Marxian concept of primitive accumulation. Then, basing on F. Chesnais, establishes the relationship of primitive accumulation with fictitious capital. Finally, points to the dialectic between the two phenomena and the D. Harvey's concept of accumulation by dispossession.

Keywords: Primitive accumulation. Fictitious Capital. Accumulation by dispossession. Political Economy 


\section{INTRODUÇÃO}

No início do século XXI, são as condições elementares da existência de bilhões de mulheres, homens e crianças que são sacrificadas cotidianamente, assim como os próprios fundamentos da reprodução da vida sobre o planeta estão ameaçados, para que os valores bursáteis continuem a satisfazer os apetites das encarnações contemporâneas do 'entesourador', esse cujo voto religioso é o de "o juro aumentar enquanto ele dorme ou está acordado, esteja ele em casa ou em viagem, de dia e de noite" (CHESNAIS, 2010, p.134).

O presente texto tem por objetivo, à luz da teoria marxista, realizar uma leitura geográfica da economia política do capitalismo contemporâneo, especialmente a crescente importância do capital fictício e sua relação com os fenômenos da acumulação primitiva e acumulação por espoliação.

Para tanto, em um primeiro momento, retoma-se a análise promovida por Karl Marx acerca da acumulação primitiva enquanto gênese do processo capitalista que opôs proprietários de dinheiro e trabalhadores livres. Destaque especial será dado à categoria terra para tentar mostrar como na economia política capitalista o título da renda da terra converte-se em uma forma do capital fictício, em detrimento do conteúdo autêntico (da terra) de ser condição de realização do trabalho, bem como suporte das atividades de produção e reprodução humana.

Secondo, da terra convertida em forma do capital fíctício desvelamos o conteúdo do capitalismo contemporâneo: o rentismo. Essa hipótese é sustentada ao longo do texto nas contribuições tripartites advindas do próprio Marx, supracitado, e dos economistas François Chesnais e Leda Paulani. Veremos como a apropriação da renda da terra, seja em ambientes urbanos ou rurais, é uma das marcas do capitalismo contemporâneo, haja vista a propriedade privada moderna garante ao proprietário privado rendimentos futuros decorrentes do trabalho social realizado.

Como defendemos a tese da financeirização da economia política capitalista contemporânea, especialmente o papel do capital fictício, retorna-se a Marx para expor os componentes do capital bancário enquanto forma de se entender o princípio da capitalização como desenvolvimento ulterior da irracionalidade do capital produtor de juros, que aprofunda o fetichismo do capital que se valoriza por si mesmo. A leitura geográfica e empírica deste processo é materializada nas ações de foro econômico do Banco Nacional de Desenvolvimento Econômico e Social (BNDES) em território maranhense, a saber, a disponibilização de dinheiro de crédito para a empresa Suzano Papel e Celulose adquirir capital fixo necessário às suas atividades produtivas $^{1}$.

Este exemplo supracitado nos servirá, também, como veremos, para tentar demonstrar como a predominância da finança na economia política capitalista contemporânea atesta a profunda relação existente entre valorização produtiva e capital fictício. As contribuições de F. Chesnais, P. Gowan e C. Serfati serão de fundamental importância nessa compreensão.

Num terceiro momento, e aprofundando ainda mais o caráter geográfico do texto ora apresentado, retomamos o conceito de acumulação por espoliação desenvolvido pelo geógrafo marxista David Harvey. Não será proferido um tratamento exegético do conceito. Pontua-se a ideia central (a criação de novos mecanismos de acumulação) sinalizando para a leitura que Harvey faz acerca da relação entre o capital fictício e a valorização 
produtiva. O caráter geográfico materializa-se nos ambientes construídos para acumulação (portos, aeroportos, ferrovias, hidrelétricas, etc.).

Nas considerações finais promovo uma recapitulação das observações ponderadas. Objetiva-se salientar a importância da Geografia, enquanto ciência, em espacializar os movimentos do capital que, por vezes, são analisados, sejam por economistas ou cientistas sociais, como estritamente temporais, anuviando, assim, o caráter geográfico do capitalismo.

\section{SOBRE ACUMULAÇÃO PRIMITIVA, CAPITAL FICTÍCIO E ACUMULAÇÃO POR ESPOLIAÇÃO}

No capital produtor de juros, a relação capitalista atinge a forma mais reificada, mais fetichista (MARX, 2008, p. 519).

Em O Capital, Karl Marx promoveu uma análise sobre a acumulação primitiva enquanto gênese do processo capitalista. A acumulação primitiva é uma "acumulação que não decorre do modo capitalista de produção, mas é seu ponto de partida" (MARX, 2011, p.827). Marx aponta a violência como marca registrada de tal processo que opôs proprietários de dinheiro e trabalhadores livres. Ou seja:

O sistema capitalista pressupõe a dissociação entre os trabalhadores e a propriedade dos meios pelos quais realizam o trabalho [...] O processo que cria o sistema capitalista consiste apenas no processo que retira ao trabalhador a propriedade de seus meios de trabalho, um processo que transforma em capital os meios sociais de subsistência e os de produção e converte em assalariados os produtores diretos (MARX, 2011, p.828).

A expropriação dos camponeses na Inglaterra lançou ao mercado uma ampla gama de proletários sem direitos. Marx (2011, p.831-832) conta ainda que "o grande senhor feudal criou um proletariado incomparavelmente maior, usurpando as terras comuns e expulsando os camponeses das terras, os quais possuíam direitos sobre elas"; Além disso, o saque dos bens da Igreja Católica com a Reforma foi um fator importante na medida em que "à época da reforma, a Igreja Católica era proprietária feudal de grande parte do solo inglês. A supressão dos conventos etc. enxotou os habitantes de suas terras, os quais passaram engrossar o proletariado" (MARX, 2011, p.835).

Mas qual a importância de destacar a questão da terra para a nossa discussão? Depois de falar da expropriação das terras camponesas e da Igreja Católica, Marx aponta que:

Os capitalistas burgueses favoreceram a usurpação, dentre outros motivos, para transformar a terra em mero artigo de comércio, ampliar a área da grande exploração agrícola, aumentar o suprimento dos proletários sem direitos enxotados das terras etc. Além disso, a nova aristocracia das terras era a aliada natural da nova bancocracia, da alta finança que acabara de romper a casca do ovo e da burguesia manufatureira que dependia então da proteção aduaneira (MARX, 2011, p. 837-838, grifos meus).

Esta extensa citação de Marx é um ponto nevrálgico de nossa análise. Mas por qual motivo? Qual a relação entre a terra e a finança de que Marx fala? É que a banconcracia inglesa desenvolveu-se a partir da usurpação/acumulação das terras, ou seja, a terra transformou-se em um ativo (uma riqueza). Onde este fenômeno pode ser facilmente visualizado já que estamos discutindo o capitalismo contemporâneo? Nas áreas urbanas e rurais a partir da apropriação da renda da terra ${ }^{2}$, receitas a partir da propriedade privada da terra. 
Harvey (2006, p.367) compreendeu isso quando escreveu:

A teoria da renda da terra resolve o problema de como a terra, o que não é um produto do trabalho humano, pode ter um preço e ser trocada como uma mercadoria. Renda da terra, capitalizada como os juros sobre um capital imaginário, constitui o valor da terra. O que é comprado e vendido não é a terra, mas o título da renda da terra gerado por ele. O dinheiro disposto é equivalente a um investimento que produza juros. $\mathrm{O}$ comprador adquire um direito sobre receitas futuras previstas, um direito sobre os frutos do trabalho. Título de terra torna-se, em suma, uma forma de capital fictício.

Dessa forma, a terra não tem valor porque não foi produzida pelo trabalho humano ${ }^{3}$; todavia, isto não impede de que ela tenha preço ${ }^{4}$. Esta é, portanto, uma das principais características do capitalismo contemporâneo: o rentismo. Explicando: a mera propriedade privada da terra garante ao seu proprietário "o direito a uma parcela do valor socialmente produzido. Dono de terra é rentista, porque a renda fundiária que lhe é devida liga-se ao fato de ser proprietário de uma dada porção do globo terrestre" (PAULANI, 2011a, p.5-6). Está assim resolvida a contradição (teoria do valor versus renda fundiária) uma vez que a terra se torna, é tratada, também como capital fictício ${ }^{5}$.

Ainda na acumulação primitiva, pode-se entender como a riqueza dos capitalistas emergentes e dos proprietários de terra pauperizou o povo pela usurpação das terras que formaram uma oligarquia. Marx, ao longo do capítulo, mostra como a lei se tornou veículo do roubo e da destituição de direitos, como a agricultura e a terra comunal foram desconectadas, a transformação da propriedade feudal em propriedade privada moderna e a alienação fraudulenta dos domínios do Estado. Somem-se a isso as legislações contra os expropriados, as leis que rebaixavam salários, leis contra trabalhadores, o sistema colonial, a participação do cristianismo e a dívida pública que:

[...] converte-se numa das alavancas mais poderosas da acumulação primitiva. Como uma varinha de condão, ela dota o dinheiro de capacidade criadora, transformando-o assim em capital, sem ser necessário que seu dono se exponha aos aborrecimentos e riscos inseparáveis das aplicações industriais e mesmo usurárias. Os credores do Estado nada dão na realidade, pois a soma emprestada converte-se em títulos de dívida pública facilmente transferíveis, que continuam a funcionar em suas mãos como se fossem dinheiro. A dívida pública criou uma classe de capitalistas ociosos, enriqueceu, de improviso, os agentes financeiros que servem de intermediários entre o governo e a nação. As parcelas de sua emissão adquiridas pelos arrematantes de impostos, comerciantes e fabricantes particulares lhes proporcionam o serviço de um capital caído do céu. Mas, além de tudo isso, a dívida pública fez prosperar as sociedades anônimas, o comércio com os títulos negociáveis de toda espécie, a agiotagem, em suma, o jogo de bolsa e a moderna bancocracia (MARX, 2011, p.868, grifos meus).

Isso prova basicamente o quê? Que a própria dívida pública é um tipo de capital fictício. Mas o que seria esse capital fictício? Para responder a esta pergunta precisamos retornar à Marx, especificamente em algumas passagens do Livro III, Volume V, d'O capital.

Depois de ter apresentado o capital produtor de juros e dissertado sobre o papel do crédito na produção capitalista $^{6}$, em capítulos anteriores, Marx, no capítulo XXIX d'O capital, intitulado componentes do capital bancário, nos apresenta o princípio pelo qual opera o capital produtor de juros: "constituir capital fictício chamase capitalizar” (MARX, 2008, p.618, grifo meu). Segundo Marx, o princípio de capitalização faz com que desapareça “o último vestígio de conexão com o processo efetivo de valorização do capital e reforça-se a ideia 
de ser o capital autômato que se valoriza por si mesmo" (idem, ibidem). É esse princípio de capitalização que permite ou possibilita que a dívida pública seja um capital fictício, ou ainda uma mercadoria.

É a onipresença da capitalização em todas as transações (o que justamente faz dela um princípio) que torna objetivo o poderio do capital portador de juros. Assim, qualquer soma de dinheiro, qualquer rendimento monetário determinado, provenha ele ou não de um capital, aparece como juro de um capital e faz surgir o capital fictício, seja ele dívida pública, ações, ou letras sobre vento [...] O princípio lógico que preside seu movimento de valorização salta de si para se difundir por todas as transações. Portanto, já não precisa ele se prender às exigências pesadas e maçantes da valorização produtiva. Além disso, os títulos de propriedade que o princípio da capitalização gera ganham um movimento autônomo, pois se transformam em mercadorias o que, segundo Marx, confirma a aparência de que eles constituem capital real (PAULANI, 2011b, p. 65).

Não é o momento ainda de comentar o conceito de acumulação por espoliação de David Harvey. Todavia, é extremamente interessante notar a persistência do mecanismo da dívida pública como uma alavanca da produção capitalista. Aquilo que Marx havia identificado no célebre capítulo da acumulação primitiva, algo que esteve nos primórdios do capitalismo, permanece no capitalismo contemporâneo. Mas, voltemos aos componentes do capital bancário, pois gostaria de ilustrar agora uma observação ponderada por Marx (2008, p.621-622, grifos meus):

A maior parte do capital bancário, portanto, é puramente fictícia e consiste em créditos (letras), títulos governamentais (que representam capital despendido) e ações (que dão direito a rendimento futuro). Não devemos esquecer que é puramente fictício o valor monetário do capital que esses títulos guardados nos cofres dos banqueiros representam - mesmo quando conferem direito a rendimentos seguros, como as apólices da dívida pública, ou constituem títulos de propriedade sobre capital real, como as ações -, e que é regulado por leis que diferem das relativas ao valor do capital efetivo representado pelo menos em parte por tais títulos. E quando esses títulos representam, em vez de capital, mero direito a rendimento uniforme, esse direito se expressa em capital-dinheiro fictício que varia sem cessar. Acresce ainda que esse capital fictício do banqueiro em grande parte não é próprio, mas do público que o deposita no banco, com ou sem juros.

Um bom exemplo que pode ser citado tem que ver diretamente com o Banco Nacional de Desenvolvimento Econômico e Social ${ }^{7}$ (BNDES). O BNDES tem apoiado os chamados "campeões nacionais" que se concentram na área de commodities (soja, minério de ferro, etc.) O BNDES, que foi criado para potencializar a industrialização brasileira, está hoje mais voltado para o financiamento de empresas de matériasprimas. O referido banco tem escolhido os setores de papel e celulose, alimentos, frigorífico, petroquímico, petróleo e mineração para receber seus vultuosos empréstimos. Exemplo: No final de 2010, a Suzano Papel e Celulose recebeu um aporte financeiro no valor de 2,7 bilhões de reais do BNDES para a construção da unidade industrial do Estado do Maranhão e, dentre outros, a implantação da infraestrutura e apoio necessário à operação desta unidade, construção de planta de cogeração de energia de biomassa, capital de giro e aquisição de máquinas e equipamentos nacionais (SUZANO, 2011). Cabe ainda destacar que no primeiro semestre de 2011, o BNDES, que atualmente mantém cerca de $4 \%$ de participação na Suzano, aprovou a disponibilização de um total de R \$ 4,4 bilhões em crédito para a companhia nos próximos anos (FONTES, 2011).

Este exemplo ilustra como o capital bancário, no caso do BNDES, está diretamente relacionado, neste caso, à valorização produtiva, uma vez que a Suzano tomou emprestado capital para ser utilizado na aquisição de 
capital fixo (instalações, máquinas, equipamentos, fábricas, etc.). Este exemplo também é bastante salutar para a afirmação de Gowan (2003) acerca da capacidade que os bancos têm de criarem dinheiro de crédito e como isto facilita a circulação das mercadorias, um fato benéfico para toda economia.

Nesse sentido, é possível visualizar e entender como capital financeiro e capital produtivo estão interligados. Gowan (2003, p.34) foi bastante lúcido em mostrar a relação entre os dois polos do capitalismo, financeiro e produtivo:

Para aquele que emprega o capital no setor produtivo, o circuito se dá da seguinte forma: o capital começa como dinheiro (parte do qual é tomado emprestado do capitalista financeiro), que é então transformado em instalações, matéria-prima e empregados no processo de produção. O capital então emerge da produção como uma massa de mercadorias para venda; quando a venda é concluída, o capital reaparece na forma de dinheiro com o excedente extraído do processo de produção. Desse excedente, o empregador paga ao capitalista financeiro a soma inicialmente adiantada, juntamente com os royalties.

A observação de Gowan permite entender que aceitar a tese da financeirização da economia não implica necessariamente rechaçar o capital/setor produtivo, mas sim que este último está subordinado ao poder da finança ${ }^{8}$.

Chesnais (2010, p.121), por sua vez, anota que: “Aquilo que parece, aos olhos do portador de títulos, ser para ele 'capital', 'seu capital', deve ser analisado como sendo uma pura ficção do ponto de vista do movimento do capital entendido como reprodução do capital produtivo". Isso demonstra a profunda interação que existe entre o capital fictício e a análise do fetichismo do capital portador de juro. No entanto, isso não nos autoriza atestar que o capital fictício não tenha implicações reais. O exemplo que demos acerca do BNDES nos mostra que os bancos jogam um papel importante no fornecimento de crédito, tal como Marx atestou no Livro III d' $O$ capital. O caminho do capital fictício pode até ser de uma crescente autonomização frente ao capital produtivo; todavia, esta autonomia relativa não é exterior ao processo de produção. De fato, o capital financeiro (finança + indústria) é base do capital fictício sobre a qual se desenvolve o processo de capitalização em vista do auferimento de rendas futuras sem necessária contrapartida para com o capital real (infraestrutura e meios de produção).

Com efeito, o crédito bancário funciona como capital fictício": "Sob a forma de adiantamentos industriais, os bancos criam meios de financiamento que desempenham o papel de capital sem o ser. Trata-se de uma forma de capital fictício" (CHESNAIS, 2010, p. 124). Mais uma vez é importante ressaltar que, por mais que o capital bancário atue como capital fictício, ele acaba sendo algo indispensável à economia capitalista mundializada. Negamos, portanto, a analítica que vislumbra uma separação entre capital fictício e capital produtivo. O que existe, em verdade, é uma confluência do capital produtivo/real com o capital fictício.

Assim, a forma de existência do capital fictício define seu conteúdo: capital sem substância de valor. O que torna a análise mais complexa é compreender como essa irracionalidade do capital fictício combina-se com o capital produtivo e torna-se indispensável ao funcionamento da economia capitalista mundializada. Logo, o que caracteriza o nosso período contemporâneo em termos da economia capitalista é a dissociação (relativa) entre a forma financeira e a forma produtiva, que tem nos grupos industriais poderosos vetores da autonomização da circulação financeira, como bem escreveu Serfati (1998).

Por fim, mas não menos importante, cabe destacar a relação entre os dois fenômenos anteriores (acumulação primitiva e capital fictício) com a acumulação por espoliação. 
A ideia central de Harvey (2010) é que além dos mecanismos tradicionais da acumulação primitiva (mercadificação da força de trabalho, privatização da terra, expropriação dos camponeses, comércio de escravos, sistema de crédito, dívida pública ${ }^{10}$ ) foram criados uma série de novos mecanismos de acumulação por espoliação, a saber: Acordo TRIPS (Agreement on Trade-Related Aspects of Intellectual Property Rights), biopirataria, mercadificação da natureza, regressão dos estatutos regulatórios destinados a proteger o trabalho, o patenteamento e licenciamento de material genético, privatização de bens públicos dantes administrados pelo Estado.

Mas qual a relação destes velhos e novos mecanismos com o capital fictício?

Em Marx, vimos como a terra transforma-se também em capital fictício o que resolve a contradição entre a teoria do valor e a existência da renda fundiária; Harvey (2010, p.97), por sua vez, atrela o capital fictício, "ativos em títulos ou notas promissórias desprovidos de suporte material, mas que podem ser usados como dinheiro", com o capital produtivo. Assim, se os gastos em ambientes construídos (portos, aeroportos, ferrovias, hidrelétricas, fábricas, etc.) ou melhorias sociais (habitações, etc.) se revelarem produtivos, os valores fictícios serão resgatados. Nesse sentido, a acumulação por espoliação libera ativos, como força de trabalho e matériasprimas, a um baixo custo com vistas a resolver o problema da sobreacumulação e assim dar um destino lucrativo ao capital empregado/despendido.

Merece destaque aqui também o sistema de crédito. Vimos com Gowan (2003) que o sistema de crédito é, de certa maneira, benéfico à economia na medida em que acelera a circulação de mercadorias e, assim, a realização do valor. Todavia, como lembra Harvey (2006, p. 288):

Aquilo que apareceu inicialmente como um saudável expediente para expressar os interesses coletivos da classe capitalista, como um meio para superar as imanentes barreiras e grilhões à produção, elevando os fundamentos materiais do capitalismo a novos níveis de perfeição, transforma-se na principal alavanca da superprodução e da super-especulação. As formas insanas de capital fictício entram em cena, possibilitando, junto ao sistema de crédito, o auge das distorções.

Do ponto de vista geográfico, podemos dizer, ainda com Harvey (2010), que o recurso ao sistema de crédito torna os territórios vulneráveis a fluxos de capitais especulativos e fictícios que podem tanto estimular, quanto solapar o desenvolvimento capitalista, ou ainda promover profundas desvalorizações, como foi o caso da Rússia, em 1998, e Argentina, em 2001.

Além do mais, geralmente, um papel pouco salientado nas investigações geográficas, diz respeito à corresponsabilização objetiva do papel dos bancos no que tange ao financiamento de projetos de desenvolvimento que promovem violações sociais e impactos ambientais nos territórios que servem como receptáculos materiais dos mesmos. E aqui cabe dedicar umas poucas linhas para exemplificar o caráter geográfico das violações. Remeterei como exemplo o financiamento do BNDES à Vale S.A. para as obras de duplicação da Estrada de Ferro Carajás ${ }^{11}$ (EFC).

Como já salientado em um trabalho anterior (SILVA; RIBEIRO JUNIOR; SANT’ANA JÚNIOR, 2011), a EFC transporta grãos, combustíveis, carvão, manganês, dentre outros produtos. Possui 892 km e corta 25 localidades, sendo 21 só no Maranhão. Diariamente passam dois tipos de trens por essa ferrovia: o trem de passageiros e o trem cargueiro, que possui 332 vagões e mais de $3.400 \mathrm{~m}$ de comprimento.

Visando aumentar a sua capacidade de escoação de ferro por ano; viabilizar a exploração da enorme jazida de Serra Sul, situada em Canaã dos Carajás - PA, a partir de 2013 e elevar o transporte de cargas de 
terceiros, a Vale está duplicando essa Estrada.

O processo de duplicação da Estrada de Ferro Carajás não envolve apenas a construção de outra linha férrea paralela à existente, mas ainda a reforma dos 57 pátios de cruzamento e a construção do píer IV, no Porto da Ponta da Madeira. Apesar das obras mencionadas fazerem parte de um único projeto, voltado para a otimização da EFC, a empreendedora solicitou junto ao IBAMA e recebeu as licenças ambientais como se fossem para obras separadas. Fragmentando o empreendimento, a Vale desobrigou-se de apresentar o EIA/RIMA (Estudo de Impacto Ambiental/Relatório de Impacto Ambiental), de fazer audiências públicas e apresentar condicionantes muito mais rigorosas.

O BNDES, por sua vez, é acionista importante da Vale S.A. e tem um assento em seu Conselho de Administração, que é ocupado por Luciano Coutinho. É também um importantíssimo financiador dos maiores projetos atuais da empresa, especialmente as obras em Carajás. É, portanto um cúmplice consciente das violações que a empresa pratica.

O que nos leva a fazer tal afirmação? Segundo informações do jornal Valor Econômico ${ }^{12}$, em agosto de 2012, o BNDES aprovou financiamento de R 3,882 bilhões para Vale S/A destinar tais recursos às obras de implantação do projeto Capacitação Logística Norte (CLN), criado para ampliar em 30,4\% a capacidade de transporte e embarque de minério de ferro do Sistema Logístico da Vale, que abrange a Estrada de Ferro Carajás (EFC) e os terminais ferroviário e marítimo de Ponta da Madeira, no Pará e no Maranhão. Com isso, o CLN passará a ter uma capacidade de 150 milhões de toneladas por ano (Mtpa).

O BNDES financiará $52,3 \%$ do projeto, que terá investimentos totais de $\mathrm{R} \$ 8$ bilhões e contempla a duplicação de aproximadamente 115 quilômetros da EFC; a aquisição de locomotivas e vagões; a construção de um novo berço de atracação (berço sul do Píer IV); e a ampliação da retroárea do terminal marítimo de Ponta da Madeira.

Todavia, no momento do fornecimento do empréstimo, as obras de duplicação da Estrada de Ferro Carajás estava suspensas pela $8^{\text {a }}$ Vara Federal do Maranhão, que mantinha paralisada a obra desde o dia 30 de julho de 2012. A paralisação das obras pelo juiz da $8^{\text {a }}$ Vara, Ricardo Felipe Rodrigues Macieira, atendia ao pedido de ação civil pública que tinha como autores a Sociedade Maranhense de Direitos Humanos (SMDH), o Conselho Indigenista Missionário (CIMI) e o Centro de Cultura Negra do Maranhão (CCN). Os autores da ação alegaram que houve violação de exigências legais do processo de licenciamento ambiental, uma vez que o projeto de duplicação da ferrovia estaria sendo desenvolvido sem o Estudo de Impacto Ambiental - Relatório de Impacto Ambiental (EIA/RIMA), documento considerado obrigatório. No entanto, a Vale entrou com recurso para suspensão da liminar junto ao Tribunal Regional Federal da $1^{\text {a }}$ Região ${ }^{13}$.

Resultado: o empréstimo concedido pelo BNDES ajudou a Vale a sustentar perante o Poder Judiciário o argumento de que o bloqueio judicial à duplicação da EFC chegava ao ponto de abalar a ordem econômica do país, na medida em que uma grande quantidade de dinheiro ( $\mathrm{R}$ \$ 3,8 bi) público já havia sido destinada à obra. Esse argumento (do abalo à ordem econômica) foi exatamente através do qual a Vale conseguiu a liberação da obra, mesmo com o Tribunal reconhecendo a ilegalidade do licenciamento e os danos ao meio ambiente e às comunidades decorrentes dessa ilegalidade ${ }^{14}$.

Este exemplo é a prova cabal da tese que sustentamos: a corresponsabilização objetiva do banco no que tange à violações sociais e impactos ambientais. Note-se, assim, que o fornecimento de dinheiro de crédito, o financiamento do BNDES, necessário à aquisição de capital fixo (instalações, máquinas, equipamentos, fábricas) 
por parte da Vale, e a formação de ambientes construídos propícios à acumulação presente e futura, tem profundas repercussões geográficas, ou melhor, rebatimentos territoriais, seja do ponto de vista do desenvolvimento econômico regional, seja do ponto de vista dos impactos territoriais concernentes aos projetos de desenvolvimento financiados, caso da duplicação da Estrada de Ferro Carajás.

\section{CONSIDERAÇÕES FINAIS}

Não foi objetivo aqui exaurir todos os possíveis questionamentos passíveis de serem feitos acerca da relação existente entre acumulação primitiva, capital fictício e acumulação por espoliação. O intuito, como tentei mostrar, foi realizar uma leitura geográfica destes três fenômenos profundamente relacionados.

Ao longo do texto julgo ter fornecido varias determinações objetivas que evidenciam o caráter geográfico dos fenômenos supracitados. A acumulação primitiva, por exemplo, muito enfatizada pelo seu aspecto lógico (intemporal) e histórico (gênese do processo capitalista), ganhou aqui contornos claramente geográficos, principalmente quando operamos com a categoria analítica terra.

Salientamos a importância da teoria da renda da terra como instrumento de leitura geográfica da realidade, e não apenas como um instrumento econômico. A teoria da renda da terra, que resolve o problema da terra não ter valor, mas possuir preço, abre espaço para a discussão do capital fictício e do rentismo, determinações da economia capitalista mundializada.

A apropriação privada de uma porção do globo terrestre com vistas a auferir rendimentos futuros sobre o valor social produzido, bem como a proeminência da finança, com crescente importância do capital fictício, nos mostra o grau de complexidade das relações econômicas no capitalismo contemporâneo.

Em termos empíricos, exemplificamos o caráter geográfico da economia atual investigando as ações de foro econômico do BNDES. O fornecimento de dinheiro de crédito para empresas como Suzano e Vale realizarem suas atividades produtivas sustentam a nossa tese de que a financeirização da economia contemporânea, apesar da tendência de autonomização, não é fenômeno exterior ao mundo da produção. Contraditoriamente, o papel preponderante da finança tem implicações reais e produtivas, especialmente se os valores fictícios não forem resgatados por meio de valorizações produtivas (construção de ambientes para acumulação, capital fixo, etc.).

Por fim, a acumulação por espoliação, que tem como função liberar ativos tais como força de trabalho e matéria-prima, é potencializado quando combinado com o capital fictício. Ofertamos como exemplo o financiamento (fornecimento de dinheiro de crédito) do BNDES à Vale para as obras da duplicação da Estrada de Ferro Carajás (ambiente construído para acumulação) que acarretou profundos rebatimentos territoriais (violações sociais e impactos ambientais em relação a camponeses e indígenas atingidos pela obra em questão). 


\section{NOTAS}

1 - Todas as informações e comentários aqui tecidos acerca da Suzano Papel e Celulose fazem parte da pesquisa de Mestrado (Pós-Graduação em Geografia Humana/FFLCH/USP) intitulada: O papelão da Suzano: Desenvolvimento, Conflitos Ambientais e Impactos sobre comunidades camponesas em Santa Quitéria (MA). A referida pesquisa está em andamento sob orientação da Profa. Dra. Marta Inez Medeiros Marques (DG/FFLCH/USP).

2 - "A renda da terra é uma categoria especial na Economia Política, porque ela é um lucro extraordinário, suplementar, permanente, que ocorre tanto no campo como na cidade. O lucro extraordinário é a fração apropriada pelo capitalista acima do lucro médio. Na indústria ele é eventual, devido ao avanço tecnológico, entretanto na agricultura ele é permanente, pois, por exemplo, existem diferenças entre a fertilidade natural dos vários tipos de solos. A renda da terra é também denominada renda territorial ou renda fundiária. Como ela é um lucro extraordinário permanente, ela é, portanto, produto do trabalho excedente. Esclarecendo melhor, o trabalho excedente é a parcela do processo de trabalho que o trabalhador dá ao capitalista, além do trabalho necessário para adquirir os meios necessários à sua subsistência. Assim, a renda da terra é uma fração da mais-valia, ou seja, é, mais precisamente, componente particular e especifico da mais-valia" (OLIVEIRA, 2007, p.43).

3 - "O trabalho, como criador de valores-de-uso, como trabalho útil, é indispensável à existência do homem quaisquer que sejam as formas de sociedade -, é necessidade natural e eterna de efetivar o intercâmbio material entre o homem e a natureza e, portanto, de manter a vida humana" (MARX, 2010, p.64-65).

4 - "A expressão simples e relativa do valor de uma mercadoria, por exemplo, o linho, através de uma mercadoria que já esteja exercendo a função de mercadoria-dinheiro, por exemplo, o ouro, é a forma preço" (MARX, 2010, p.92, grifo meu).

5.-. Nas palavras de Chesnais (2010, p.99): "Esse termo designa os títulos que foram emitidos no momento dos empréstimos em dinheiro a entidades públicas ou a empresas ou como expressão da participação dos primeiros participantes no financiamento do capital de uma empresa. Para seus detentores, esses títulos, ações e obrigações, representam um 'capital' do qual eles esperam um rendimento regular sob a forma de juros e dividendos (uma 'capitalização') e que eles desejam poder vender em um espaço de tempo muito curto, seja em caso de necessidade de dinheiro, seja para aplicar de maneira ainda mais rentável. Entretanto, no momento em que eles são vistos sob o ângulo do movimento do capital entendido como capital produtivo de valor e de maisvalia, esses títulos não são capital. No melhor dos casos, são a 'lembrança' de um investimento feito há muito tempo. No momento de crashs e outras crises de mercado financeiro, esse caráter fictício dos títulos se revela e se desvaloriza às custas de seus detentores. Mas anteriormente esses títulos podem ter servido de fundamento a operações que somente fizeram a ficção ampliar".

6 - A saber: 1) Facilitar a equalização da taxa de lucro, 2) Reduzir o custo de circulação, 3) Formação da sociedade por ações.

7 - Criado no Governo Getúlio Vargas pela Lei $\mathrm{n}^{\circ} 1.628$ de 20 de junho de 1952, o Banco Nacional de Desenvolvimento Econômico (BNDE) atuou (e atua) fortemente no direcionamento do processo de industrialização do País no contexto da substituição de importações tanto como financiador, quanto como formulador e definidor de novos parâmetros econômicos. Apenas em 1982 que o Banco passou a se chamar Banco Nacional de Desenvolvimento Econômico e Social (BNDES). O "S", que até então não existia, surge com o argumento de reforçar o caráter público e social de uma instituição federal que compreendeu o desenvolvimento como sinônimo de crescimento econômico, atendendo a interesses privados/particulares enclavistas, num âmbito estritamente economicista.

8 - Segundo Chesnais (2010, p.100), finança expressa "as instituições especializadas na centralização do dinheiro 'inativo' em busca de colocação em empréstimos ou em títulos, isto é, os fundos de pensão e de aplicação coletiva ou Mutual Funds, as grandes empresas de seguro e os maiores bancos, e as estruturas institucionais".

9 - Nos apoia também Chesnais (2008, p.29) em outro texto: "El crédito creado por los bancos conlleva también una dimensión de creación de capital ficticio, y aunque asume diversas formas y puede ser más o menos importante, significa en definitiva que los bancos ponen a disposición de 'los agentes económicos' sumas que no tienen". 
10 - Não podemos nunca esquecer aquilo que escreveram Rotta e Paulani (2009, p.630): “Crédito está totalmente conjugado à formação de capital fictício através da dívida estatal”.

11 - Segundo Ribeiro Junior e Sant'Ana Júnior, “Desde 1976, ano em que o decreto no 77.608 outorgou a Vale a concessão para a construção, uso e exploração da Estrada de Ferro entre Carajás (PA) e a capital do Maranhão (São Luís), a Vale tem atuado diretamente e indiretamente no espaço maranhense, fato esse que tem contribuído decisivamente para a promoção de impactos socioambientais (desde poluição atmosférica até deslocamento de populações).

12

http://www.valor.com.br/brasil/2800766/bndes-aprova-r-39-bilhoes-para-vale-investir-nomaranhao\#ixzz2MmTDmNU8

13 - Conforme informações extraídas do sítio eletrônico: http://padrebombieri.blogspot.com.br/2012/08/bndesfinancia-eu-nao-vale.html

14.-. Agradeço ao advogado da Rede Justiça nos Trilhos, Danilo Chammas, pelos esclarecimentos jurídicos dessa questão. 


\section{REFERÊNCIAS}

CHESNAIS, François. El fin de un ciclo. Alcance y rumbo de la crisis financiera. In: Vários autores. Primeiro dossiê de textos marxistas sobre a crise mundial. Grupo de Pesquisa Políticas para o Desenvolvimento Humano do Programa de Estudos Pós-graduados em Economia Política. Sociedade Brasileira de Economia Política, 2008, p.14-43.

CHESNAIS, F. "A proeminência da finança no seio do 'capital em geral', o capital fictício e o movimento contemporâneo de mundialização do capital". In: CHESNAIS, F. et alii, Finança Capitalista. São Paulo: Alameda Editorial, 2010, p.95-246.

FONTES, Stella. Suzano tem mais de R \$ 4 bilhões à mão no BNDES. Valor Econômico [online], São Paulo, 06 maio 2011. Disponível em: <http://www.valoronline.com.br/impresso/empresas/102/423053/suzano-tem-maisde-r-4-bilhoes-a-mao-no-bndes>. Acesso em: 20 jul. 2011.

GOWAN, Peter. A Roleta Global. Rio de Janeiro: Record, 2003.

HARVEY, David. Limits to Capital. London: Verso, 2006.

HARVEY, David. O novo imperialismo. Trad. Adail SOBRAL e Maria Stela GONÇALVES. $4^{a}$ ed. Loyola: São Paulo, 2010.

MARX, Karl. O Capital: crítica da economia política, livro I. Trad. Reginaldo SANT'ANNA. 27a ed. Rio de Janeiro: Civilização Brasileira, 2010.

MARX, Karl. O Capital: crítica da economia política, livro primeiro: o processo de produção do capital, volume II; Trad. Reginaldo SANT'ANNA. 25ªed. Rio de Janeiro: Civilização Brasileira: 2011.

MARX, Karl. O Capital: crítica da economia política, livro terceiro: o processo global de produção capitalista, volume V; Trad. Reginaldo SANT’ANNA. Rio de Janeiro: Civilização Brasileira: 2008.

OLIVEIRA, Ariovaldo Umbelino. Modo de Produção Capitalista, Agricultura e Reforma Agrária. São Paulo: FFLCH, 2007, 184p.

PAULANI, Leda Maria. Acumulação e Rentismo: resgatando a teoria da renda de Marx para pensar o capitalismo contemporâneo. Inédito. 2011a.

PAULANI, L. M. "A Autonomização das Formas Verdadeiramente Sociais na Teoria de Marx: comentários sobre o dinheiro no capitalismo contemporâneo". EconomiA, Brasília(DF), v.12, n.1, p.49-70, jan/abr 2011b.

RIBEIRO JUNIOR, José Arnaldo dos Santos; SANT'ANA JÚNIOR, Horácio Antunes. A política de desenvolvimento sustentável da Vale. Geografia Ensino \& Pesquisa, v. 15, n.3, p. 726, set./dez. 2011.

ROTTA, Tomas Nielsen; PAUlAnI, L. M. A Teoria Monetária de Marx: Atualidade e Limites Frente ao Capitalismo Contemporâneo. Economia, Brasília(DF), v.10, n.3, p.609-633, set/dez 2009.

SERFATI, Claude. "O Papel Ativo dos grupos Predominantemente Industriais na Financeirização da Economia". In: CHESNAIS, François (org.) A Mundialização Financeira. São Paulo, Xamã, 1998.

SILVA, Sislene Costa da; RIBEIRO JUNIOR, J. A. S; SANT'ANA JÚNIOR, H. A. Projetos de desenvolvimento e conflitos territoriais no espaço amazônico maranhense: a duplicação dos trilhos da Estrada de Ferro Carajás e os impactos socioambientais nas comunidades quilombolas de Santa Rosa dos Pretos e Monge Belo em Itapecuru-mirim. In NAHUM, João Santos (organizador). Anais do V Simpósio Internacional e VI Simpósio Nacional de Geografia Agrária, 7 a 11 de novembro de 2011. Belém: Açaí, 2011. 